\title{
Unidades de Conservação no Ecótono entre Pantanal e Cerrado: o caso do Município de Aquidauana (MS)
}

Lidiane Perbelin Rodrigues $^{(\text {a) }}$, Elisângela Martins de Carvalho ${ }^{(\mathrm{b})}$, Jaime Ferreira da Silva ${ }^{(\mathrm{c})}$

(a) Universidade Federal de Mato Grosso do Sul, lidiane_perbelin@hotmail.com

(b) Universidade Federal de Mato Grosso do Sul, elisangela.carvalho@ufms.br

(c) Universidade Federal de Mato Grosso do Sul, jaime.ferreira@ufms.br

\section{EIXO: BIOGEOGRAFIA, MANEJO DE ÁREAS NATURAIS E PROTEGIDAS: CONSERVAÇÃO DA BIODIVERSIDADE}

\begin{abstract}
Resumo:
As Unidades de Conservação (UCs) despontam no cenário mundial como forma legitima de proteger a biodiversidade ao final do século XX. No Brasil, o SNUC - Sistema Nacional de Unidades de Conservação da Natureza, dá fomento à criação dessas Unidades de Conservação. A gestão territorial de Unidades de Conservação situadas em regiões de importância ambiental como o Pantanal Sul-mato-grossense e o Cerrado que o circunda, tem papel fundamental para a proteção da biodiversidade. O presente trabalho buscou diagnosticar as Unidades de Conservação do município de Aquidauana-MS, visando subsidiar o planejamento ambiental. Para a elaboração do trabalho utillizou-se de informações obtidas junto a Prefeitura Municipal e pelo Instituto de Meio Ambiente de Mato Grosso do Sul (IMASUL). Durante a pesquisa, verificou-se a grande disparidade entre a situação legal e ambiental das UC's do município de AquidauanaMS.
\end{abstract}

Palavras chave: Pantanal; Cerrado; Biodiversidade; Planejamento Ambiental..

\section{Introdução}

O Pantanal é uma extensa área úmida situada na grande bacia sedimentar Quaternária localizada na parte central da Bacia do Alto Paraguai (BAP), circundada por Planaltos recobertos por Cerrados e penetrados por Florestas Galerias. É a parte central da depressão do Alto Paraguai, e constitui uma planície heterogênea, entendida como paisagem de exceção (AB'SÁBER, 2006).

Já o domínio dos Cerrados representa um domínio zonal, de primeira grandeza espacial, com área nuclear que se estende por todo o planalto central brasileiro. O domínio possui como característica grandes altitudes, cabeceira de drenagem em anfiteatro, presença de plainos de erosão e plataformas estruturais escalonadas, além de solos pobres em condições topográficas e climáticas favoráveis (AB'SÁBER, 2003).

Apesar das diferenças marcantes, esses Domínios possuem correlações quanto aos aspectos geomorfológicos e fitogeográficos, principalmente em sua porção localizada em Mato Grosso do Sul. 
Além das características ambientais, os aspectos sociais também se relacionam, tendo em vista que o processo de ocupação do Cerrado afeta o Pantanal, e vice-versa, principalmente no que tange a ocupação mais recente, a partir da década de 1970, período de expansão da fronteira agrícola, Revolução Verde, êxodo rural, e revitalização da rede urbana do centro oeste, além de forte corrente migratória sulista. A ocupação desordenada das regiões de planalto ocorrida a partir de então gerou aceleramento dos processos erosivos, perda de biodiversidade, contaminação e poluição dos recursos hídricos também no Pantanal.

Diante do exposto, emerge a necessidade da adoção de medidas que busquem proteger o Pantanal e suas áreas circunvizinhas.

Nesse sentido, a criação de Unidades de Conservação da Natureza, buscando preservar e/ou conservar esta biodiversidade apresenta-se como uma alternativa viável, que entretanto precisa ser realizada com planejamento e eficiência.

Norteado pelas normas estabelecidas pelo Institui o Sistema Nacional de Unidades de Conservação da Natureza (SNUC), o presente trabalho visa analisar as condições ambientais e legais das Unidades de Conservação (UC's) existentes no município de Aquidauana-MS, que situa-se exatamente na área de transição entre o Planalto e a Planície Pantaneira.

Buscou-se analisar se essas UC's encontram-se em conformidade com a legislação vigente, e se vem cumprindo seu papel de proteger a esta região, assim como sugerir propostas para o gerenciamento ambiental eficiente do meio ambiente e ordenamento territorial para fim de equacionar as questões de características ambientais e fornecer dados para orientações futuras, que busquem a solução de questões envolvendo o meio ambiente.

\section{Material e Métodos}

Durante a elaboração deste trabalho os procedimentos metodológicos adotados consistiram em estudos, trabalhos estatísticos, cartografia e análise de textos e documentos sobre o objeto de estudo.

Buscaram-se documentos junto aos órgãos governamentais, tais como Instituto de Meio Ambiente de Mato Grosso do Sul e a Prefeitura Municipal de Aquidauana, e documentação direta e através de pesquisa de campo, efetuou-se trabalho de reconhecimento da área e inventário dos dados atinentes ao trabalho.

Para o mapeamento das UC's utilizou-se dos memoriais descritivos contidos nos documentos de criação das mesmas, assim como a base cartográfica municipal, estadual, nacional e da América do Sul disponibilizada pelo IBGE (2015), além da delimitação do Pantanal elaborada por Silva et al (2007). 


\section{Resultados e Discussão}

\subsection{Localização e Caracterização da área de estudo}

O município de Aquidauana está localizado à porção centro-oeste do estado de Mato Grosso do Sul, compreendido entre as latitudes de $18^{\circ} 35^{\prime} 18.2893^{\prime \prime} \mathrm{S}$ e $20^{\circ} 30^{\prime} 50.3655^{\prime \prime S}$ e longitudes $56^{\circ} 59^{\prime} 57.9281$ "W e $55^{\circ} 03^{\prime} 32.3429$ "W. Como característica marcante, Aquidauana encontra-se situada na área de transição entre a Planície Pantaneira e o Planalto de Maracajú-Campo Grande (Conforme Figura 1), o que the confere uma vasta biodiversidade, característica de regiões de ecótono.

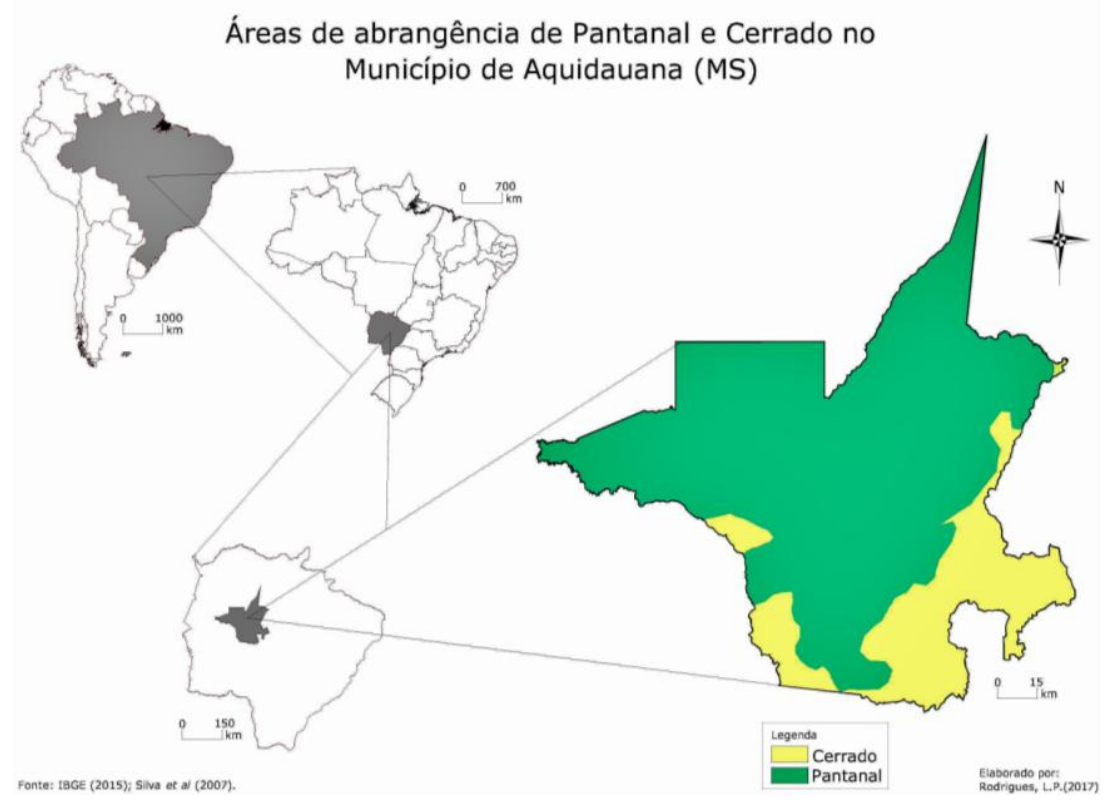

Figura 1 - Áreas de Abrangência de Pantanal e Cerrado no Município de Aquidauana (MS)

Com população de 45.615 hab e território de $16.000 \mathrm{~km}$, o município de Aquidauana possui densidade demográfica de $2.69 \mathrm{hab} / \mathrm{km}^{2}$, entretanto, esses habitantes encontram-se concentrados especialmente em sua área urbana ( $78 \%$ de população urbana), o que torna sua área rural ainda menos povoada, principalmente o que tange ás áreas de Pantanal.

As áreas rurais do município encontram-se dominadas por grandes propriedades rurais, que tem como principal atividade econômica a pecuária, que para seu desenvolvimento exigem grandes áreas de pastagem, sejam naturais ou cultivadas.

Cappi (2001) salienta que a realização de atividades agropecuárias favorecem a ocorrência dos processos erosivos, além de contaminação das águas superficiais e subterrâneas, acarretando num desequilíbrio dos geossistemas, comprometendo a biodiversidade. 
Nesse sentido, para ajudar na conservação e preservação da diversidade existente no município a criação de Unidades de Conservação passa a ser vista como um método plausível.

\subsection{Unidades de Conservação do Município de Aquidauana}

Segundo dados obtidos junto a Prefeitura Municipal de Aquidauana, no município existem dez unidades de conservação instituídas (Figura 1). Dessas unidades, quatro estão situadas em região de Pantanal e seis em região de Cerrado.

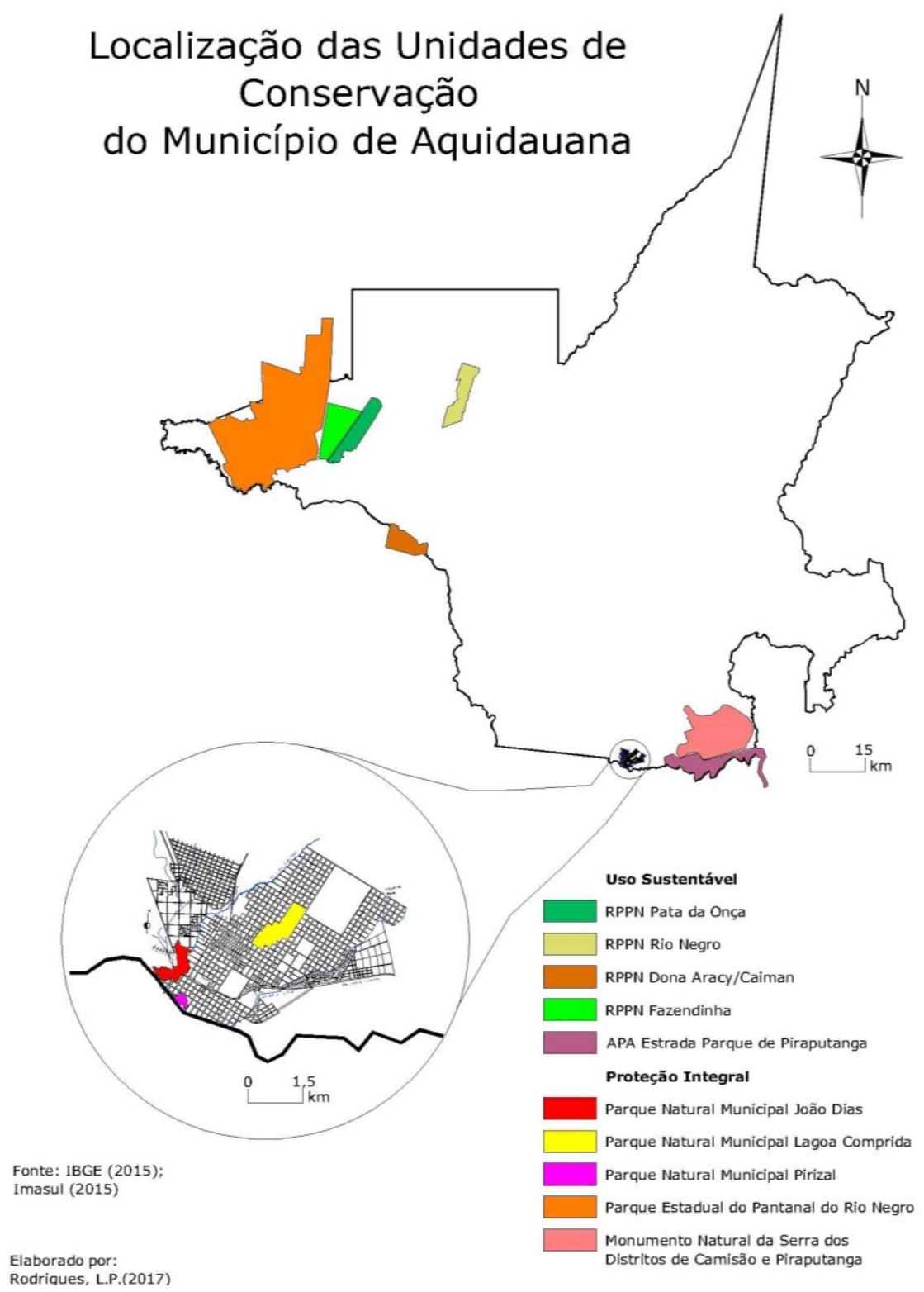

Figura 2. Localização das Unidades de Conservação do Município de Aquidauana 


\subsection{Unidades de Conservação da Categoria Uso Sustentável}

Dentre as Unidades de Conservação existentes no município de Aquidauana, cinco pertencem a Categoria de Uso Sustentável, onde se visa compatibilizar a conservação da natureza com o uso sustentável de parcela dos seus recursos naturais (SNUC, 2001).

\subsection{1 Área de Proteção Ambiental (APA) Estrada Parque de Piraputanga}

Criada através do Decreto Estadual n 9.937/2000, a Área de Proteção Ambiental Estrada Parque de Piraputanga localiza-se entre as latitudes sul de $20^{\circ} 26^{\prime} 13.1697 "$ e $20^{\circ} 32^{\prime} 5.2206^{\prime \prime}$ e as longitudes oeste $55^{\circ} 41^{\prime} 22.1062 "$ e $55^{\circ} 24^{\prime} 52.7948 "$ do meridiano de Greenwich. A APA possui área de $10.16 \mathrm{~km}^{2}$ e está parcialmente inserida no município de Aquidauana (77\%), e o restante (23\%) insere-se no município de Dois Irmãos do Buriti. No interior da Unidade situam-se dois distritos do município de Aquidauana, Camisão e Piraputanga, e um distrito de Dois Irmãos do Buriti, Palmeiras.

A APA encontra-se implantada as margens do Rio Aquidauana, afluente do rio Miranda, e pertencente a Bacia Hidrográfica do Alto Paraguai, numa região de Planalto e formação de escarpas oriundas do processo de intemperismo sofrido pelas litologias locais, notadamente o Arenito Aquidauana.

Tal configuração garante à APA uma beleza cênica que atrai turistas para a região. A criação de roteiros para visitação e mirantes apresenta-se como estratégia viável. Cabe ressaltar que nesta unidade há passagem da Estrada de Ferro Noroeste do Brasil, rota do Trem do Pantanal, com paradas em Estações de cada um dos distritos existentes na APA.

A APA não possui plano de manejo cadastrado, pois este encontra-se ainda em fase de elaboração. Além disso, em visita técnica a UC, realizada no mês de Abril de 2016, foram observados outros problemas, tais como a falta de sinalização de inicio ou término da Unidade e as vias de acesso a UC encontram-se em estado precário de conservação, favorecendo a ocorrência de acidentes de transito.

Rodrigues et al (2015) ao analisar o uso e cobertura da terra na APA entre os anos de 2000 e 2014, confirmaram que desde sua criação a APA vem tendo dificuldade de cumprir seu papel de proteger a biodiversidade da área, visto nos 5 primeiros posteriores a sua criação a APA perdeu 33\% de sua vegetação remanescente, que em 2000 cobriam 52,2\% da área total, e em 2014 restavam apenas 32,6\% de vegetação nativa na APA, enquanto às pastagens utilizadas para criação bovina extensiva ocupavam $61,6 \%$ da área. 


\subsubsection{Reserva Particular do Patrimônio Natural (RPPN) Fazendinha}

A RPPN Fazendinha é a UC mais antiga do município de Aquidauana, e uma das pioneiras do Pantanal Sul-Mato-Grossense. Localizada entre as latitudes sul de $19^{\circ} 33^{\prime} 33.1075^{\prime \prime S}$ e $19^{\circ} 42^{\prime} 57.1382^{\prime \prime S}$ e as longitudes oeste $56^{\circ} 28^{\prime} 14.0773^{\prime \prime} \mathrm{W}$ e $56^{\circ} 35^{\prime} 44.1563$ "W do meridiano de Greenwich, a Unidade foi criada em 17 de Junho de 1994 pela Portaria de Reconhecimento 065/94 do Governo Federal e conta com uma área de $9.61 \mathrm{~km}^{2}$.

Sua paisagem pantaneira possibilita-lhe o desenvolvimento do ecoturismo, apesar do evidente potencial, ele não vem sendo aproveitado, visto que não é desenvolvida nenhuma atividade turística nesta UC.

Esta RPPN possui posição estratégica para a conservação, pois localiza-se entre o Parque Estadual do Pantanal do Rio Negro e a RPPN Pata da Onça compondo assim, um importante complexo de áreas protegidas em pleno Pantanal, contribuindo para a preservação e conservação desse bioma. Essas UCS situam-se num vale entre os rios Negro e Aquidauana, numa sub-região do Pantanal conhecida como Pantanal do Rio Negro.

A unidade apresenta-se irregular perante o IMASUL, órgão competente do estado para a fiscalização das UC's, pois não possui Plano de Manejo. Esse importante instrumento precisa ser elaborado para melhor administração da Unidade garantindo assim que a Fazendinha cumpra o papel à qual foi criada.

\subsubsection{Reserva Particular do Patrimônio Natural (RPPN) Pata da Onça}

Criada pela Secretaria de Estado através da Deliberação CECA-MS nº 02/1999, a RPPN Santa Sophia possui $9.3 \mathrm{~km}^{2}$. Localizada às latitudes $19^{\circ} 32^{\prime} 40.3074 " \mathrm{~S}$ e $19^{\circ} 43^{\prime} 26.2778^{\prime \prime S}$ e as longitudes

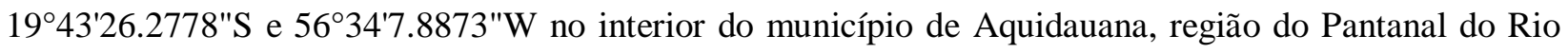
Negro.

Essa RPPN apresenta grande beleza cênica, mas possui acesso dificultado devido as suas condições naturais, o que atrapalha o desenvolvimento do turismo ou pesquisas cientificas, sendo realizado com tranquilidade entre os meses de maio e setembro, período de seca no Pantanal. A sede da RPPN encontrase de 140 quilômetros distantes da cidade de Aquidauana, acesso através de estradas vicinais, que utilizando veículo com tração nas quatro rodas pode durar entre três e cinco horas. O acesso por via fluvial através do Rio Aquidauana não é usual, e a viagem dura dois dias (WWF Brasil, 2004). 
A RPPN não possui Plano de Manejo cadastrado, o que faz-se necessário para que a partir do cumprimento da legislação, esta possa cumprir adequadamente seu papel na conservação do Pantanal.

\subsubsection{Reserva Particular do Patrimônio Natural (RPPN) Dona Aracy/Caiman}

Localizada as latitudes $19^{\circ} 53^{\prime} 11.2323 " S$ e $19^{\circ} 21^{\prime} 27.2772 "$ Se as longitudes $56^{\circ} 17^{\prime} 2.4690^{\prime \prime S ~ e ~}$ 56 24'5.2498"W, a RPPN Dona Aracy/Caiman possui 6.5 $\mathrm{km}^{2}$ sendo menor RPPN do município. De sua área total, 28,42\% encontra-se situada em Aquidauana e 71,57\% situada no município de Miranda, em área de Cerrado, mas em baixas declividades e altitudes.

A beleza cênica e os serviços de pousadas, trilhas e passeios nela oferecidos atraem turistas nacionais e internacionais, possuindo dessa forma uma atividade turística consolidada.

Sua portaria de criação é anterior à instituição do SNUC, e por esse motivo foi enquadrada no novo sistema juntamente como a Reserva Particular do Patrimônio Natural Fazendinha e a Reserva Particular do Patrimônio Natural Pata da Onça.

Atualmente, a RPPN Dona Aracy/Caiman é uma das três unidades de conservação do município de Aquidauana com um Plano de Manejo legalmente instituído, o que contribui para a manutenção e divulgação dos serviços nela prestados, assim como a conservação ambiental nessa área de Cerrado.

\subsubsection{Reserva Particular do Patrimônio Natural (RPPN) Rio Negro}

A RPPN Rio Negro é uma das fazendas mais tradicionais do município de Aquidauana e apresenta uma das melhores situações legais dentre as UC's abrangidas por esta pesquisa.

Criada pela Deliberação CECA n ${ }^{\circ}$ 010/2001, portanto já no período de vigência do SNUC, ela encontra-se regularmente cadastrada e possui Plano de Manejo. A Unidade é a segunda menor RPPN do município, com apenas $7.0 \mathrm{~km}^{2}$.

Nela, são desenvolvidas projetos de pesquisas em parceira com diversas instituições. Situada no Pantanal, às margens do Rio Negro, que a atravessa à porção sul, e localizada as latitudes $19^{\circ} 28^{\prime} 10.5620^{\prime \prime S}$ e $19^{\circ} 37^{\prime} 51.4628^{\prime \prime} \mathrm{S}$ e as longitudes $56^{\circ} 16^{\prime} 8.6338^{\prime \prime} \mathrm{W} 56^{\circ} 10^{\prime} 18.1889^{\prime \prime} \mathrm{W}$, alcança o objetivo de conservar a biodiversidade pantaneira. 
Dotada de uma beleza cênica exuberante, nela são desenvolvidas atividades turísticas tais como cavalgadas, trilhas, passeio de canoa, turismo de contemplação, hotel e restaurante (WWF BRASIL, 2004).

\subsection{Unidades de Conservação da Categoria Proteção Integral}

As Unidades de Conservação da Categoria Proteção Integral possuem objetivo básico de preservar a natureza, nelas, apenas o uso indireto dos recursos naturais é permitido (SNUC, 2000)

\subsubsection{Monumento Natural da Serra dos Distritos de Camisão e Piraputanga}

Criado em 29 de maio de 2007 através do Decreto Municipal n 072/2007, o Monumento Natural da Serra dos Distritos de Camisão e Piraputanga localiza-se as latitudes $20^{\circ} 19^{\prime} 42.0342^{\prime \prime S}$ e $20^{\circ} 27^{\prime} 57.8819^{\prime \prime S}$ e as longitudes oeste $55^{\circ} 27^{\prime} 09.6813^{\prime \prime} \mathrm{W}$ e $55^{\circ} 39^{\prime} 26.4763 \mathrm{~W} \mathrm{~W}$, em plena região de Planalto do município de Aquidauana. Trata-se da UC mais recentemente criada no município. Sua situação junto ao IMASUL é irregular, e não há um plano de manejo cadastrado.

Em sua área de $20.81 \mathrm{~km}^{2}$, assim como na APA Estada Parque de Piraputanga, existem áreas de intensa dinâmica geomorfológica, havendo formação de escarpas.

Nele são desenvolvidas atividades agropecuárias, havendo regiões de pastagem e áreas cultivadas. Em seu interior existem plantações de eucalipto, o que representa uma espécie invasora dentro do bioma cerrado, a qual a unidade encontra-se. Há uma grande necessidade de restringir-se o avanço desse processo, que pode ser extremamente prejudicial para a fauna e flora local, assim como, a recuperação das áreas degradadas pela agricultura e pecuária.

A beleza natural observada na UC pode trabalhar a favor da sua conservação, atraindo turistas e gerando renda para as populações locais. A implantação de mirantes pode ser feita sem a necessidade de grandes investimentos, como no Mirante no Morro Santa Bárbara, que também atenderia a APA Estrada Parque de Piraputanga. O turismo de contemplação, o Geoturismo e o incentivo a pesquisa poderiam trazer grandes avanços no sentido de desenvolver a região e manter a rica biodiversidade ali encontrada. 
XVII Simpósio Brasileiro

de Geografia Fisica Aplicada

I Congresso Nacional

de Geografia Física
OS DESAFIOS DA GEOGRAFIA FÍSICA NA FRONTEIRA DO CONHECIMENTO

Instituto de Geociências - Unicamp

Campinas - SP

28 de Junho à 02 de Julho de 2017

\subsubsection{Parque Estadual do Pantanal do Rio Negro}

Localizado na região conhecida como Pantanal do Rio Negro, as latitudes de 19²1'27.3253"S e $19^{\circ} 47^{\prime} 51.6832$ "S e as longitudes $56^{\circ} 33^{\prime} 20.6161 " \mathrm{~W}$ e $56^{\circ} 52^{\prime} 54.1731$ "W e formado por $77.9 \mathrm{~km}^{2}$ hectares, o Parque Estadual do Pantanal do Rio Negro é a maior UC do município de Aquidauana. Está situado no limite entre Aquidauana, que detém $78 \%$ da sua área e Corumbá, que detém os $22 \%$ restantes.

Com criação datada em 5 de junho de 2000, através do Decreto no 9.941 do Governo do Estado de Mato Grosso do Sul, o Parque Estadual do Pantanal do Rio Negro encontra-se regular perante ao IMASUL, com Plano de Manejo devidamente aprovado e Zona de Amortecimento consolidada (Portaria no 098/09, de 03/02/2009).

O Parque Estadual é a única Unidade de Proteção Integral na região do Pantanal da Nhecolândia e do Rio Negro, por isso apresenta-se como refugio para animais e plantas da região e somadas sua área a das RPPNs existentes em seu entorno, são mais de 100.000 hectares protegidas, formando o maior complexo de áreas protegidas do estado (Plano, 2008, apud ABDON, 2009).

\subsubsection{Parque Natural Municipal (PNM) João Dias}

Com área de 47,29 hectares e localizado as latitudes de $20^{\circ} 28^{\prime} 42.3854^{\prime \prime} \mathrm{S}$ e $20^{\circ} 28^{\prime} 58.0284^{\prime \prime} \mathrm{S}$ e as

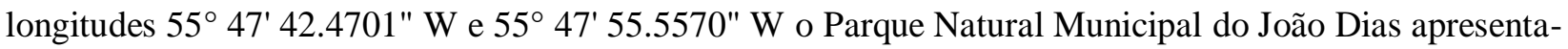
se cercado por áreas antropizadas do sitio urbano de Aquidauana, na área de abrangência do Cerrado. Sua delimitação, obtida através do memorial descritivo, contido no seu Decreto de criação, no 087/2001 de 30 de julho de 2001, ignora áreas verdes importantes e inclui em seus limites áreas urbanizadas.

Além disso, a entrada e saída do Parque não têm nenhum controle, visto que não existe nenhum tipo de fiscalização. Suas terras encontram-se inseridas em área de propriedade privada existentes anteriormente a sua criação, a remoção desses proprietários é algo inacessível. Os usos nele estabelecidos não são compatíveis com a categoria de Unidade de Proteção Integral.

O Parque sofreu historicamente diversos impactos oriundos dessa proximidade. As lagoas existentes na área do Parque, por exemplo, não são naturais, mas sim oriundas da extração de argila para o abastecimento das olarias da cidade (FERNANDES et al, 2013 a). Na área Há pontos de descarte de lixo, além de caça e pesca realizada pelos moradores dos Bairros Vila Trindade, Nova Aquidauana e Vila Cidade Nova, que o circunda. 


\subsubsection{Parque Natural Municipal (PNM) Lagoa Comprida}

A Lagoa Comprida é reconhecida como um dos cartões postais da cidade de Aquidauana, sendo considerada uma das mais belas paisagens encontradas na área urbana de do município, com vegetação típica do Cerrado, atrai os moradores locais para a realização de atividades esportivas e de lazer, até mesmo a existência de moradias e animais domesticados como bovinos, equinos e animais de estimação, entretanto, essas atividades estão em desconformidade com o SNUC, que passou a regulamentar a área a partir da instituição do decreto $\mathrm{n}^{\circ}$ 089/2001, que cria o ali o Parque Natural Municipal da Lagoa Comprida.

Localizada as latitudes $20^{\circ} 27^{\prime} 15.3459^{\prime \prime} \mathrm{S}$ e $20^{\circ} 27^{\prime} 59.2971^{\prime \prime} \mathrm{S}$ e as longitudes $55^{\circ} 45^{\prime} 20.55 .7209^{\prime \prime} \mathrm{W}$ e 55 46' 46.3597" W, o PNM Lagoa Comprida possui 75,86 hectares, e encontra-se totalmente cercado pela área urbana, fato que lhe causa impactos negativos, e foi constatada a inexistência do Plano de Manejo.

No Parque entrada e saída de visitantes não obedece nenhum critério, tanto para aqueles que se disponha a admirá-la ou realizar um Cooper na pista de corrida nela existente, tanto para aqueles que depositam lixo ou ateiam fogo em seu entorno.

\subsubsection{Parque Natural Municipal (PNM) Pirizal}

Com área de 10,32 hectares, Parque Natural Municipal (PNM) Pirizal é a menor Unidade de Conservação localizada no município. Localizado as latitudes $20^{\circ} 28^{\prime} 42.3854^{\prime \prime} \mathrm{S}$ e $20^{\circ} 28^{\prime} 58.0284^{\prime \prime} \mathrm{S}$ e ás longitudes $55^{\circ} 47^{\prime} 42.4701 "$ W e 55 47' 55.5570" W, o Parque foi criado em 30 de julho de 2001 através do Decreto Municipal no 085/2001.

O PNM Pirizal situa-se as margens do Rio Aquidauana, cerca de $21 \%$ de sua área corresponde à APP do rio. Apesar de se localizar na área de abrangência do Cerrado, em épocas de cheias, toda a sua extensão é inundada pelas águas do Aquidauana, funcionando assim como zona de escape e há em seu interior um espelho d'água perene, proveniente do Sangradouro da Lagoa Comprida e esgoto doméstico lançadas no canal.

O entorno do Parque é urbanizado, constando em seu interior irregularidades fundiárias, onde toda sua área encontra-se loteada. Em seu interior há construção de prédios comerciais e residenciais, e em seu entorno há depósitos de lixo. 
A situação do PNM Pirizal não condiz com os objetivos de uma UC, necessitando da realização de um amplo trabalho de recuperação e planejamento, o qual devem ser envolvidos tanto os gestores públicos, como a população local.

\section{Considerações finais}

Ao analisarmos a problemática das Unidades de Conservação do município de Aquidauana pudemos notar a falta de preocupação quanto às análises preliminares a instalação das mesmas. É essencial que se preconize pelos conceitos técnicos ao se criar uma Unidade e não apenas pelos apelos econômicos e/ou políticos, pois tais interesses tornam-se vãos ao entrarmos ao campo da pratica, e muitas vezes acabam gerando problemas muito maiores do que aquelas existentes.

Durante a pesquisa, foi detectada a falta de documentos cartográficos em escalas adequadas ao planejamento das Unidades, demonstrando a falta de conhecimento profundo sobre as mesmas. Este mapeamento mais detalhados, seria essencial para compreender a dinâmica de uma UC, tornando mais eficaz a gestão ambiental garantindo a preservação e conservação das espécies nelas existentes.

Mesmo com os problemas destacados, enfatiza-se a necessidade de realização de um esforço para a adequação legal dessas unidades no intuito de equacionar os problemas ambientais e administrativos das unidades visto a grande relevância ambiental da biodiversidade do município de Aquidauana.

Diante do exposto, justifica-se a necessidade do planejamento das ações antrópicas sobre esses domínios. O planejamento busca encontrar a melhor maneira de se alcançar determinado objetivo, e no caso dos domínios Cerrado e Pantanal, deve-se buscar um equilíbrio entre o desenvolvimento social e econômico com a conservação ambiental. Realizar a gestão ambiental no município é zelar pelo futuro do Pantanal e do Cerrado em Mato Grosso do Sul.

\section{Bibliografia}

AB'SABER, A. N. Os domínios de natureza no Brasil: potencialidades paisagísticas. São Paulo: Ateliê Editorial, 2003.

ABDON, M de M. ; SILVA, J. dos S. V. da. ; POTT, A. ; POTT, V. J. ; SILVA, M. P.da.; MENGATTO JUNIOR, E. A.; Cobertura vegetal do Parque Estadual Pantanal do Rio Negro (PEPRN) - MS. Anais $2^{\circ}$ Simpósio de Geotecnologias no Pantanal, Corumbá, 7-11 novembro 2009, Embrapa Informática Agropecuária/INPE, p.674-684.

AB'SÁBER, A. N. Brasil: Paisagens de Exceção - O litoral e o Pantanal mato-grossense. São Paulo: Ateliê Editorial, 2006.

BRASIL. Decreto n ${ }^{\circ}$.922/1996. Criação da Reserva Particular do Patrimônio Natural Dona Aracy/Caiman. 
BRASIL. Lei $n^{\circ}$. 9.985, de 18 de julho de 2000. Institui o Sistema Nacional de Unidades de Conservação da Natureza (SNUC), e dá outras providências. Diário Oficial da República Federativa do Brasil, Brasília, DF, jul. 2000 .

CAPPI, Nanci. Implicações do Uso e Ocupação do Solo na qualidade das águas subterrâneas das bacias dos córregos Fundo e Santa Maria/MS. 2002. 113fls. Dissertação (Mestrado em Geografia) - Universidade Federal de Mato Grosso do Sul, Dourados-MS.

DSG. Serviço Geográfico do Exército. Cartas Topográficas. Região Centro-Oeste. 1966.

FERNANDES, E. F. de L. ;Silva, J. F.da. ;Ayach, L. R. Rodrigues, L. P. Souza, I. M. Subsídio para o diagnóstico do Parque Natural Municipal do João Dias. - Semana da Geografia UFMS/CPAq - 2013a. (CD ROM)

IBGE. Instituto Brasileiro de Geografia e Estatística. Arquivos Shapefiles 2015. Disponível em: <http://goo.gl/sd6GFo>. Acesso em 15 de Nov. 2015.

MATO GROSSO DO SUL. Decreto N 9.941, De 5 De Junho De 2000. Cria o Parque Estadual do Pantanal do Rio Negro e dá outras providências.

MATO GROSSO DO SUL. Portaria n ${ }^{0}$ 098/09, de 03/02/2009. Cria a Zona de Amortecimento do Parque Estadual do Pantanal do Rio Negro e dá outras providencias.

MATO GROSSO DO SUL. Secretaria de Estado Deliberação CECA-MS n 010/2000. Criação da Reserva Particular do Patrimônio Natural Rio Negro.

MATO GROSSO DO SUL. Secretaria de Estado Deliberação CECA-MS nº 02/1999. Criação da Reserva Particular do Patrimônio Natural Pata da Onça.

PREFEITURA MUNICIPAL DE AQUIDAUANA. Decreto Municipal no 072/2007 de 29 de maio de 2007. Criação do Monumento Natural da Serra dos Distritos de Camisão e Piraputanga.

PREFEITURA MUNICIPAL DE AQUIDAUANA. Decreto Municipal nº 085./2001 de 30 de julho de 2001. Criação do Parque Natural Municipal do Pirizal.

PREFEITURA MUNICIPAL DE AQUIDAUANA. Decreto Municipal no 087/2001 de 30 de julho de 2001.Criação do Parque Natural Municipal do João Dias.

PREFEITURA MUNICIPAL DE AQUIDAUANA. Decreto Municipal no 089/2001 de 30 de julho de 2001. Criação do Parque Natural Municipal da Lagoa Comprida.

RODRIGUES, L.P; SILVA, J. F; CARVALHO, E. M. de. Análise multitemporal do uso e cobertura da terra da Área de Proteção Ambiental Estrada Parque de Piraputanga - Aquidauana/MS. Revista Equador (UFPI), Vol. 4, No 3, (2015). Edição Especial XVI Simpósio Brasileiro de Geografia Física Aplicada. Teresina- Piauí.

SILVA, João dos Santos Vila da; ABDON, Myrian de Moura; SILVA, Ariadiny Monteiro da; SOUZA, Letícia Azevedo de; Banco de dados de vegetação do projeto PROBIO-PANTANAL. In: CONGRESSO BRASILEIRO DE CARTOGRAFIA. 23. 2007, Rio de Janeiro, Brasil: Anais... Rio de Janeiro, RJ. 2007./p.1643-1652. Disponível em $<$ https://goo.gl/pT4XO3> Acesso em: 29 abr. 2016.

WWF BRASIL. RPPNs na Bacia do Alto Paraguai - Brasil: catálogo. [Coord. Bernadete Lage eAnaluce Freitas] Brasília, DF, WWF Brasil, 2004. 51p. 